\title{
Determinantes da violência sexual infantil no estado do Paraná - Brasil
}

\author{
Determinants of child sexual violence in the state of Paraná - Brazil
}

Determinantes de la violencia sexual infantil en el estado del Paraná-Brazil

Gabriela de Araujo ${ }^{1}$, Marina Ramos ${ }^{2}$, Tânia Zaleski ${ }^{3}$, Leandro Rozin ${ }^{4}$,

Leide da Conceição Sanches ${ }^{5}$

\author{
${ }^{1}$ Estudante de Medicina da Faculdades Pequeno Príncipe . Curitiba - Paraná \\ ${ }^{2}$ Estudante de Medicina da Faculdades Pequeno Príncipe . Curitiba - Paraná \\ ${ }^{3}$ Mestre e Doutora em Zoologia pela Universidade Federal do Paraná. Faculdades Pequeno Príncipe \\ Curitiba - Paraná \\ ${ }^{4}$ Mestre em Biotecnologia Aplicada à Saúde da Criança e do Adolescente - Faculdades Pequeno \\ Príncipe . Curitiba - Paraná \\ ${ }^{5}$ Doutora em Sociologia pela Universidade Federal do Paraná. Docente do Programa de Mestrado \\ em Ensino nas Ciências da Saúde da Faculdades Pequeno Príncipe . Curitiba - Paraná
}

\section{RESUMO}

A violência sexual infantil configura-se como um fenômeno sociocultural, pautado em relações hierárquicas e desigualdades de gênero, étnico-raciais e geracionais. Nesta pesquisa, investigouse os determinantes da violência sexual infantil a partir dos casos notificados pelo SINAN no estado do Paraná entre 2011 e 2014, disponibilizados pelo DATASUS, por estudo descritivo, de base documental e abordagem quantitativa. No Paraná, totalizaram 2.446 casos no período. A

Autor de Correspondência:

*Leide da Conceição Sanches. E-mail: leide.sanches@fpp.edu.br 
Regional de Saúde com maior prevalência foi a de Foz do Iguaçu. Prevalece a faixa etária de 5 a 9 anos, meninas, raça negra e indígenas. Na tipologia, predominaram estupro e assédio sexual, por meio de força corporal. Os casos prevalentemente ocorreram na residência e o provável agressor era próximo da criança. Reconhecer os determinantes da violência sexual infantil é essencial para a implementação de ações de cuidado integral às vítimas.

Palavras-chave: Abuso Sexual na Infância. Violência Sexual. Fatores Epidemiológicos.

\begin{abstract}
Child sexual violence is a sociocultural phenomenon based on hierarchical relationships and gender, ethnic-racial and generational inequalities. This research investigated the determinants of child sexual violence based on the cases reported by SINAN in the state of Paraná between 2011 and 2014, made available by DATASUS, through a descriptive study, of documentary basis and quantitative approach. In the state of Paraná, there were 2446 cases in the period. The most prevalent Health Unit was that of Foz do Iguaçu. The age range of 5 to 9 years, girls, black race and indigenous are prevalent. In the typology, rape and sexual harassment by the use of force predominated. The cases predominantly occurred at home, and the likely perpetrator was close to the child. Recognizing the determinants of child sexual violence is essential for the implementation of comprehensive care actions for victims.
\end{abstract}

Keywords: Child Abuse, Sexual. Sex Offenses. Epidemiologic Factors.

\title{
RESUMEN
}

La violencia sexual infantil es un fenómeno sociocultural, basado en las relaciones jerárquicas y las desigualdades de género, étnico raciales y generacionales. En esta investigación, los determinantes de la violencia sexual infantil fueron investigados a partir de los casos reportados por SINAN en el estado de Paraná entre 2011 y 2014, proporcionados por DATASUS, por estudio descriptivo, base documental y enfoque cuantitativo. En Paraná, hubo 2446 casos en el período. La Región Sanitaria con mayor prevalencia fue Foz de Iguazú. El grupo de edad de 5 a 9 años, niñas, negros e indios prevalece. En la tipología, predominó la violación y el acoso sexual a través de la fuerza corporal. Los casos prevalecieron en la residencia y el probable agresor estaba cerca del niño. Reconocer los determinantes de la violencia sexual infantil es esencial para la implementación de acciones de atención integral a las víctimas.

Palabras clave: Abuso Sexual Infantil. Delitos Sexuales. Factores Epidemiológicos. 


\section{INTRODUÇÃO}

Todo ato ou jogo sexual com intenção de estimular sexualmente a criança ou o adolescente é considerado violência sexual. Com o objetivo de utilizá-lo para obter satisfação sexual, em que os autores da violência estão em estágio de desenvolvimento psicossexual mais adiantado que a criança ou adolescente. As situações de violência sexual são variadas e podem ocorrer como estupro, incesto, assédio sexual, exploração sexual, pornografia, pedofilia, manipulação de genitália, mamas e ânus, ato sexual com penetração, imposição de intimidades, exibicionismo, "voyeurismo" (obtenção de prazer sexual por meio da observação), jogos sexuais e práticas eróticas não consentidas e impostas ${ }^{1}$.

É comum que a violência inicie de forma menos invasiva, como a sedução e o abuso sem contato físico, evoluindo progressivamente para formas com contato físico e penetração vaginal e anal embora isso não seja um padrão ${ }^{1}$. As primeiras investidas podem ser percebidas pela criança como uma demonstração afetiva, de maneira que o agressor usa da inocência da vítima para inferir a normalidade dos atos. Com o tempo, a frequência dos abusos aumenta e a vítima passa a sentir insegurança. Quando a criança suspeita ou entende sobre o abuso, o agressor inverte os papéis, fazendo com que ela se sinta culpada. Além disso, usa de ameaças diversas para exigir o silêncio².

Sabe-se que a ocorrência da violência sexual durante o processo formativo, quando o cérebro está sendo fisicamente desenvolvido, pode deixar marcas em sua estrutura e função, provocando efeitos que alteram, de modo irreversível, o desenvolvimento neuronal, levando a severas consequências para o desenvolvimento da criança, incluindo prejuízos cognitivos, emocionais, comportamentais e sociais ${ }^{3}$.

A temática da violência sexual infantil adquiriu maior expressão no advento da consolidação do Estatuto da Criança e do Adolescente (ECA), na década de 1990. Sua criação impulsionou a maior participação dos movimentos políticos e sociais, das Organizações
Não Governamentais (ONGs) e a criação de Fóruns e Conselhos na garantia dos direitos das crianças e adolescentes. A aprovação do ECA foi consequência de um marco que representou a Constituição Federal de 1988 na afirmação dos direitos da criança e do adolescente, os quais passaram de uma visão de "objeto" para sujeitos de direitos ${ }^{4}$.

A favor da efetivação do ECA, surge o Conselho Nacional dos Direitos da Criança e do Adolescente (CONANDA), com a responsabilidade de implementar Conselhos estaduais e municipais, de Direito e Tutelares. Em junho de 1993, surge o Relatório da primeira Comissão Parlamentar Mista de Inquérito (CPMI), para investigar as redes de exploração sexual de crianças, evidenciando a falta e necessidade da criação de políticas públicas básicas e de atendimento às vítimas ${ }^{1,4}$.

O Plano Nacional de Enfrentamento da Violência Sexual Contra Crianças e Adolescentes, produzido pelo Ministério da Justiça, tem como finalidade incentivar ações que possibilitem intervenções para o combate à violência contra crianças e adolescentes ${ }^{4}$. No ano de 2011, com a publicação da Portaria no 104 de 2011 do Ministério da Saúde, tornou-se obrigatória a notificação da violência como fator que contribuiu para o grande aumento de municípios notificantes da violência infantil em âmbito nacional, justificando o aumento do número de casos notificados com o passar dos anos 5 .

De acordo com a Ficha de Notificação de Violência Doméstica, Sexual e/ou Outras Violências Interpessoais, proposta pelo Sistema de Vigilância de Violências e Acidentes (VIVA) do Ministério da Saúde e utilizada para notificação dos casos de violência sexual infantil em serviços de saúde, pela qual se registrou os dados analisados e discutidos nesta pesquisa, constam, no descritivo de violência sexual da Ficha, cinco opções de marcação para o tipo da violência sexual ocorrida, sendo eles: assédio sexual, estupro, pornografia, exploração sexual e outros. 
A identificação da violência contra as crianças suscita a necessidade de protegê-las, e esta ação se inicia oficialmente a partir da notificação, a qual é considerada compulsória, e a partir disso é possível investigar vários fatores relacionados à violência, tornando a notificação um poderoso instrumento de política pública ${ }^{4-5}$.

O processo de preenchimento da ficha de notificação não deve ocorrer de maneira insensível, mas sim com postura ética, representando um momento de atenção e cuidado com a pessoa violentada. A notificação possibilita a criação de um elo entre a área da saúde e o sistema legal, com formação de uma rede multiprofissional e interinstitucional de atuação $0^{1,4,6}$.

Diante das peculiaridades que envolvem a violência sexual infantil, reconhecida como uma questão social e de saúde pública devido à magnitude da violação aos direitos humanos, o estudo teve por objetivo investigar os determinantes de violência sexual infantil a partir dos casos notificados por meio do Sistema de Informação de Agravos de Notificação (SINAN) no estado do Paraná.

\section{MÉTODO}

Pesquisa descritiva, de base documental e com abordagem quantitativa, realizada a partir de dados preexistentes, oriundos dos registros das fichas de notificação do Sistema de Informação de Agravos de Notificação (SINAN) - de Violência Doméstica, Sexual e/ou Outras Violências Interpessoais, disponibilizados por meio do Departamento de Informática do Sistema Único de Saúde (DATASUS).

Os dados de notificação dos casos de violências são coletados a partir dos serviços de saúde, que encaminham uma via da notificação para a Vigilância Epidemiológica das Secretarias Municipais de Saúde, seguindo para a Secretaria Estadual de Saúde (SESA) e para o Ministério da Saúde, entidades que também são responsáveis pela retroalimentação e divulgação desses dados. O Ministério da Saúde disponibiliza os dados por meio do Departamento de Informática do Sistema Único de Saúde (DATASUS), sistema que concentra as informações epidemiológicas, sanitárias e de morbimortalidade ${ }^{7}$.

Dessa forma, a coleta dos dados ocorreu a partir das notificações dos casos de violência infantil no estado do Paraná, realizadas na Ficha de Notificação de Violência Doméstica, Sexual e/ou Outras Violências Interpessoais.

Como critérios de inclusão foram selecionados dados específicos de violência do tipo sexual, praticada contra crianças com idade entre 0 e 9 anos, notificados no estado do Paraná entre os anos disponíveis que foram de 2011 a 2014 disponibilizadas em banco de dados do Data-SUS. Os dados coletados foram o número de casos de violência sexual infantil por ano de notificação; regionais de saúde de notificação; faixa etária, sexo e raça das crianças violentadas sexualmente; local de ocorrência e meio de agressão da violência sexual; tipo de violência sexual; e vínculo-grau de parentesco com o provável autor da violência. Os dados demográficos da população de crianças residente nos locais, gênero, cor ou raça, faixa etária, para os municípios e estado, foram obtidos através dos dados públicos disponibilizados pelo IBGE.

Após a coleta, os dados foram planilhados no Software Excel ${ }^{\circledR}$ e foram agrupados por ano de notificação; regionais de saúde de notificação; faixa etária, sexo e raça das crianças violentadas sexualmente; local de ocorrência e meio de agressão da violência sexual; tipo de violência sexual; e vínculo-grau de parentesco com o provável autor da violência. Os dados foram analisados por meio do cálculo da Taxa de Prevalência (TP), com constante a cada 10 mil crianças com idade entre 0 e 9 anos e comparados através do teste de frequência quiquadrado, assumindo um alfa de $5 \%$.

\section{RESULTADOS}

No período de 2011 a 2014, foram notificados 2.446 casos de violência sexual contra crianças no Paraná. 
Observou-se aumento no número de notificações nos anos subsequentes a 2011, com acréscimo percentual de $153 \%$ de 2011 para 2012 e de $235 \%$ de 2011 para $2014(\mathrm{p}<0,01)$.

Ao verificar os números absolutos de casos, a maioria foi notificada na Regional de Saúde (RS) Curitiba/Metropolitana, com 1.501 casos, seguida pela RS de Foz do Iguaçu, com 281 casos e pela RS de Maringá, com 145 casos. Contudo, ao considerar a população residente em cada regional de saúde, a maior prevalência se deu na RS de Foz do Iguaçu, com 47,51 casos a cada 10.000 crianças, seguida por RS Curitiba/Metropolitana 32,80 casos/10.000 crianças e RS Maringá com 15,83 casos/10.000 crianças (Tabela 1).

Tabela 1 - Distribuição dos casos de violência sexual infantil no Paraná entre 2011 e 2014 segundo as regionais de saúde de notificação.

\begin{tabular}{|c|c|c|c|}
\hline Regional de Saúde do Paraná & $\mathbf{N}^{*}$ & Pop. Censo** & Prevalência/ $\mathbf{1 0 . 0 0 0}$ crianças \\
\hline 9ª RS Foz do Iguaçu & 281 & 59.140 & 47,51 \\
\hline $2^{\text {a }}$ RS Metropolitana & 1.501 & 457.684 & 32,80 \\
\hline 15ª RS Maringá & 145 & 91.619 & 15,83 \\
\hline $17^{\mathrm{a}} \mathrm{RS}$ Londrina & 115 & 114.839 & 10,01 \\
\hline 21를 RS Telêmaco Borba & 27 & 29.064 & 9,29 \\
\hline 10 ${ }^{\mathrm{a}}$ RS Cascavel & 65 & 72.483 & 8,97 \\
\hline $20^{\mathrm{a}}$ RS Toledo & 42 & 47.234 & 8,89 \\
\hline $7^{\text {a }}$ RS Pato Branco & 32 & 38.217 & 8,37 \\
\hline $22^{\mathrm{a}} \mathrm{RS}$ Ivaiporã & 16 & 19.578 & 8,17 \\
\hline $4^{\mathrm{a}}$ RS Irati & 20 & 24.764 & 8,08 \\
\hline $16^{\mathrm{a}} \mathrm{RS}$ Apucarana & 34 & 46.246 & 7,35 \\
\hline $13^{\mathrm{a}}$ RS Cianorte & 12 & 18.813 & 6,38 \\
\hline 5ª RS Guarapuava & 37 & 71.830 & 5,15 \\
\hline $8^{\mathrm{a}}$ RS Francisco Beltrão & 20 & 46.666 & 4,29 \\
\hline $3^{\text {a }}$ RS Ponta Grossa & 38 & 92.454 & 4,11 \\
\hline 1ª RS Paranaguá & 14 & 42.702 & 3,28 \\
\hline 19ª RS Jacarezinho & 12 & 38.791 & 3,09 \\
\hline $12^{\mathrm{a}} \mathrm{RS}$ Umuarama & 8 & 34.146 & 2,34 \\
\hline 6를 RS União da Vitória & 6 & 26.131 & 2,30 \\
\hline 14ª RS Paranavaí & 6 & 35.463 & 1,69 \\
\hline 11를 RS Campo Mourão & 7 & 44.960 & 1,56 \\
\hline 18ª RS Cornélio Procópio & 4 & 29.605 & 1,35 \\
\hline Total & 2.442 & 1.482 .429 & 16,47 \\
\hline
\end{tabular}

Dados: *Ministério da Saúde/SVS - Sistema de Informação de Agravos de Notificação - Sinan Net | ${ }^{* *}$ Censo 2010. 
Ao agrupar os dados das características individuais das crianças que sofreram violência sexual, optouse também por calcular a prevalência, para que fossem obtidos resultados fidedignos de acordo com a população específica da faixa etária estudada. $\mathrm{Na}$ Tabela 2 , verificou-se que as crianças com idade entre 5 e 9 anos foram as mais violentadas, com $56,8 \%$ dos casos e prevalência de 18,09 a cada 10 mil crianças. Entre os sexos, a maior frequência é verificada nas meninas $(69,6 \%$; $\mathrm{TP}=23,40 / 10.000)$.

Referente à raça e etnia, verificou-se maior frequência de notificações nas crianças brancas $(66,8 \%)$, seguidas das pardas $(18 \%)$, pretas $(3,1 \%)$, indígenas $(0,4 \%)$ e amarelas $(0,3 \%)$. No entanto, quando se analisa a prevalência entre as raças das crianças, a preta prevalece com $28,37 / 10.000$, seguida das indígenas 20,54/10.000 (Tabela 2).

Tabela 2 - Distribuição dos casos de violência sexual infantil, segundo faixa etária, sexo e raça no estado do Paraná, entre 2011 e 2014.

\begin{tabular}{|c|c|c|c|c|c|}
\hline & $\mathbf{N}^{*}$ & $\%$ & Pop. Censo ${ }^{* *}$ & Prevalência/10.000 crianças & Valor de $\mathbf{p}$ \\
\hline \multicolumn{6}{|c|}{ FAIXA ETÁRIA } \\
\hline$<1$ Ano & 63 & 2,6 & 144.631 & 4,36 & \multirow{3}{*}{0,01} \\
\hline 1 a 4 Anos & 993 & 40,6 & 569.406 & 17,44 & \\
\hline 5 a 9 Anos & 1.390 & 56,8 & 768.392 & 18,09 & \\
\hline Total & 2.446 & 100 & 1.482 .429 & 16,50 & \\
\hline \multicolumn{6}{|l|}{ SEXO } \\
\hline Masculino & 744 & 30,4 & 754.736 & 9,86 & \multirow{2}{*}{0,01} \\
\hline Feminino & 1.702 & 69,6 & 727.204 & 23,40 & \\
\hline Total & 2.446 & 100 & 1.481 .940 & 16,51 & \\
\hline \multicolumn{6}{|l|}{ RAÇA } \\
\hline Preta & 76 & 3,1 & 26.793 & 28,37 & \multirow{6}{*}{$<0,01$} \\
\hline Indígena & 10 & 0,4 & 4.869 & 20,54 & \\
\hline Branca & 1.634 & 66,8 & 1.063 .593 & 15,36 & \\
\hline Parda & 440 & 18 & 374.623 & 11,75 & \\
\hline Amarela & 7 & 0,3 & 12.004 & 5,83 & \\
\hline Ign/Branco & 279 & 11,4 & - & - & \\
\hline Total & 2.446 & 100 & 1.481 .940 & 14,25 & \\
\hline
\end{tabular}

Dados: *Ministério da Saúde/SVS - Sistema de Informação de Agravos de Notificação - Sinan Net. ${ }^{* *}$ Censo 2010. 
O estupro prevaleceu em $41,8 \%$ dos casos conforme o tipo de violência sexual, seguido pelo assédio sexual com 33\%. O meio de agressão mais frequente foi força corporal/espancamento em $43,1 \%$ dos casos.
A residência foi o principal local de ocorrência da violência sexual infantil, com $71,6 \%$ dos casos notificados (Tabela 3).

Tabela 3 - Distribuição dos casos de violência sexual infantil, conforme o tipo de violência sexual, meio de agressão e local de ocorrência, no estado do Paraná, entre 2011 e 2014.

\begin{tabular}{|c|c|c|c|}
\hline & $\mathbf{N}$ & Frequência \% & Valor de $p$ \\
\hline \multicolumn{4}{|l|}{ TIPO DE VIOLÊNCIA SEXUAL } \\
\hline Estupro & 1.045 & 41,8 & \multirow{6}{*}{$<0,01$} \\
\hline Assédio sexual & 825 & 33,0 & \\
\hline Atentado violento ao pudor & 271 & 10,8 & \\
\hline Pornografia infantil & 110 & 4,4 & \\
\hline Exploração sexual & 67 & 2,7 & \\
\hline Outras violências & 182 & 7,3 & \\
\hline Total & 2.500 & 100,0 & \\
\hline \multicolumn{4}{|l|}{ MEIO DE AGRESSÃO } \\
\hline Força corporal/espancamento & 587 & 43,1 & \multirow{7}{*}{$<0,01$} \\
\hline Ameaça & 495 & 36,4 & \\
\hline Objeto contundente & 23 & 1,7 & \\
\hline Enforcamento & 9 & 0,7 & \\
\hline Objeto perfuro-cortante & 8 & 0,6 & \\
\hline Arma de fogo & 8 & 0,6 & \\
\hline Outro & 231 & 17 & \\
\hline Total & 1.361 & 100 & \\
\hline \multicolumn{4}{|l|}{ LOCAL DE OCORRÊNCIA } \\
\hline Residência & 1.752 & 71,6 & \\
\hline Escola & 151 & 6,2 & \\
\hline Via pública & 57 & 2,3 & \\
\hline Habitação Coletiva & 13 & 0,5 & \\
\hline Comércio/Serviços & 11 & 0,4 & \\
\hline Local de prática esportiva & 6 & 0,2 & \\
\hline Bar ou Similar & 4 & 0,2 & \\
\hline Indústrias/construção & 4 & 0,2 & \\
\hline Outros & 210 & 8,6 & \\
\hline Ignorado / Em branco & 238 & 9,7 & \\
\hline Total & 2.446 & 100 & \\
\hline
\end{tabular}

Dados: Ministério da Saúde/SVS - Sistema de Informação de Agravos de Notificação - Sinan Net. 
Na Tabela 4, são apresentados dados do provável autor da violência. Observou-se em relação ao vínculo/grau de parentesco, que o item de outros vínculos da Ficha de Notificação (correspondente a qualquer outro(a) provável autor(a) não contemplado(a) nas outras categorias presentes) predominou com 31,1\% dos casos. Em seguida, 18,3\% referiram amigo(a) ou conhecido(a) como o provável agressor, $17,8 \%$ atribuíram a violência ao pai da criança, $11,1 \%$ ao padrasto, $5,6 \%$ ao irmão ou irmã, 5,5\% à mãe e 5,3\% a um desconhecido(a).

Tabela 4 - Distribuição dos casos de violência sexual infantil segundo vínculo/grau de parentesco com o provável autor da violência, no estado do Paraná, entre 2011 e 2014.

\begin{tabular}{|c|c|c|c|}
\hline Vínculo / Grau de parentesco & $\mathrm{N}$ & Frequência \% & Valor de $\mathrm{p}$ \\
\hline Outros vínculos & 766 & 31,1 & \multirow{14}{*}{$<0,01$} \\
\hline Amigo(a)/Conhecido(a) & 450 & 18,3 & \\
\hline Pai & 438 & 17,8 & \\
\hline Padrasto & 274 & 11,1 & \\
\hline $\operatorname{Irmão(ã)}$ & 138 & 5,6 & \\
\hline Mãe & 136 & 5,5 & \\
\hline Desconhecido(a) & 130 & 5,3 & \\
\hline Cuidador(a) & 73 & 3 & \\
\hline Pessoa com relação institucional & 39 & 1,6 & \\
\hline Madrasta & 7 & 0,3 & \\
\hline Namorado(a) & 4 & 0,2 & \\
\hline Própria Pessoa & 3 & 0,1 & \\
\hline Cônjuge & 2 & 0,1 & \\
\hline Ex-Namorado(a) & 1 & 0,04 & \\
\hline Total & 2.461 & 100 & \\
\hline
\end{tabular}

Dados: Ministério da Saúde/SVS - Sistema de Informação de Agravos de Notificação - Sinan Net.

\section{DISCUSSÃO}

A publicação da Portaria no 104 de 2011 do Ministério da Saúde tornou obrigatória a notificação da violência, fator que contribuiu para o grande aumento de municípios notificantes da violência infantil em âmbito nacional, justificando o aumento do número de casos notificados com o passar dos anos. Dados do Sistema de Vigilância de Violência e Acidentes (VIVA/SINAN) de abrangência nacional demonstram aumento no número de casos notificados no Brasil, sendo 4.577 no ano de 2010, 5.675 no ano de 2011 e 8.450 casos notificados em 2013 constatando aumento de $84 \%$ entre 2010 e $2013^{4-5}$. 
Durante os anos analisados neste estudo, considerase que a notificação ainda estava com sua implantação em curso no Paraná e no Brasil, dessa forma, os dados podem subestimar a realidade da violência no Paraná, evidenciando apenas uma parte do problema. Contudo, os resultados já apontam elementos que contribuem para a compreensão do perfil epidemiológico da violência no estado, já que o Sistema de Notificação apresenta grande potencial de contribuição para visibilidade da violência ${ }^{5,7-8}$.

A violência sexual infantil em Foz do Iguaçu associase a problemas de escolaridade, empregabilidade e desigualdades de gênero, geracionais, étnicoraciais e sociais, fenômenos presentes na sociedade e intensificados pela exploração e turismo sexual encontrados na região da tríplice fronteira ${ }^{9}$.

O mapa da violência contra crianças e adolescentes realizado por WAISELFISZ em $2012^{10}$, apontou que 4 cidades da Regional de Saúde Metropolitana/Curitiba estão entre as primeiras 70 no Ranking Nacional da Violência Sexual, são elas: Piraquara (11aㅡ), São José dos Pinhais (39a), Almirante Tamandaré (42ª) e Araucária (69aㅡ), sendo a capital Curitiba, a $8^{\underline{a}}$ mais violenta do país.

Outros estudos também identificaram como resultado a idade mais avançada como prevalente para a violência infantil, ocorrendo na faixa etária de 6 a 9 anos. Há menor frequência em crianças menores de 1 ano, em comparação com as outras faixas etárias ${ }^{11-12}$. Pesquisas que incluíram adolescentes - com 10 anos ou mais de acordo com a definição da Organização Mundial da Saúde - demonstraram maior frequência de violência sexual na faixa etária de 10 a 15 anos $^{12-14}$. Verificou-se também que os meninos são violentados em faixas etárias mais precoces e o número vem aumentando com o passar dos anos e as meninas em idades mais tardias ${ }^{15}$.

O predomínio do sexo feminino na violência sexual também é encontrado em diversos países e culturas. Um estudo realizado em 21 países constatou que as meninas apresentam o dobro de chance de serem sexualmente violentadas, em comparação aos meninos ${ }^{5,11}$. Estudos realizados em todo o território brasileiro, também demonstram que a maioria dos casos de violência sexual são contra meninas. Almeida, Sousa e Sousa ${ }^{16}$ analisaram o perfil da violência sexual contra crianças em Teresina (PI), entre os anos 2007 e 2016 e observaram que $92 \%$ das crianças violentadas sexualmente eram meninas.

O predomínio do sexo feminino nos casos de violência sexual infantil já foi apontado por diversos autores, com maior prevalência delas nos estados de São Paulo (SP) e Rio de Janeiro (RJ), e nos municípios de Curitiba (PR), Ribeirão Preto (SP), Londrina (PR), Belém (PA), Feira de Santana (BA), Florianópolis (SC), Botucatu (SP) e Tubarão (SC) $)^{5,11,13,16-18}$.

Esses dados refletem que a violência sexual infantil pode ser entendida como violência de gênero, reflexo da desigualdade histórica entre homens, mulheres e meninas na sociedade. Condição de subordinação da mulher e a suposta fragilidade feminina, ideia da mulher fraca, submissa, passiva, em contrapartida ao homem, forte, viril, racional, conceitos perpetrados ao longo de décadas que necessitam de solução quanto aos valores sociais, frente à violência, fazendo com que o sexo feminino seja o mais acometido ${ }^{16}$. A vulnerabilidade das mulheres e meninas, pautada na ideia de uma suposta fragilidade feminina, está assimilada culturalmente desde os primeiros anos de infância e perpassa por uma desigualdade geracional2, ${ }^{217-19}$.

O termo raça, utilizado pelo IBGE, designa as diferenças relativas à cor de pele, tipo de cabelo, conformação facial e cranial, ancestralidade e genética. Em estudo nacional de Rates e Cols ${ }^{5}$, concluiu-se que as crianças negras (pretas), são as mais violentadas sexualmente, ao considerar a frequência e a prevalência. Em alguns estudos, no centro sul do Brasil, a maior frequência foi na raça branca, e na região nordeste prevalece a maior frequência em negros ${ }^{5,12-14,16-20}$. Entretanto, salientase que em nenhum desses estudos se considerou a 
taxa da prevalência da população, reduzindo sua confiabilidade por não calcular a raça que sofreu a violência de maneira comparativa com o total existente na região do estudo.

A violência e vitimização tendem a seguir um padrão étnico, tendo os negros e indígenas como destaques, haja vista que esses ocupam lugares divergentes na sociedade, quando comparados aos brancos. Apresentam experiências desiguais, com desequilíbrios que levam os negros à diversas iniquidades sociais, expressas pelas desigualdades social e racial. Esse processo determina condições de vulnerabilidade, especialmente à violência, desconsiderando as desvantagens simbólicas e materiais $^{16,21}$.

A maior frequência de abuso e exploração sexual comercial em regiões litorâneas, turísticas e fronteiras internacionais apontam o turismo sexual como fator facilitador da exploração de crianças, relação também discutida nesta pesquisa com a maior prevalência na Regional de Foz do Iguaçu. A exploração sexual comercial e a pornografia possuem como fatores predisponentes a falta de uma educação de qualidade, a pobreza e miséria, a violência e a má distribuição de renda ${ }^{19}$. Historicamente a exploração sexual se relaciona com atividades econômicas territoriais, exemplificando os bordéis próximos a garimpos, as "acompanhantes" de políticos e executivos perto dos centros políticos e administrativos, entre outros, e destaca que a ilegalidade e o poder econômico do mercado do sexo dificultam as pesquisas sobre este tipo de violência ${ }^{14,20}$.

No estudo de Oliveira e cols ${ }^{14}$ também se demonstrou alta incidência de uso de intimidação por meio de ameaça, em 40,3\% dos casos, e de força física em $25,2 \%$. Os meios de agressão relacionados à violência sexual revelam a coocorrência com outros tipos de violência (física e psicológica), simultaneamente. A violência sexual é também violência física e psicológica e discute sobre a categorização dos tipos de violência, para fins de compreensão do fenômeno, ser também um fator de confusão, pois na prática as classificações são pouco excludentes entre si.

Muitos estudos também mostram que o domicílio é o principal local em que ocorre a violência sexual infantil, e, associando-se ao agressor como pessoa próxima da criança violentada, muitas vezes da própria família, contrapõe-se à visão do ambiente familiar como um local de segurança, proteção e acolhimento da criança ${ }^{5,13-15,18-20}$.

As informações encontradas na literatura sobre violência sexual contra crianças corroboram com os dados desta pesquisa sobre a predominância do autor da violência ser uma pessoa próxima ou conhecida da vítima ou da família, ou membro da família, e do sexo masculino ${ }^{13-14,18}$.

Citar o agressor como apenas "conhecido" pode ser consequência do medo de revelar o real agressor, como forma de negação da violência ocorrida e proteção da unidade familiar, principalmente pela mãe, que teria que escolher entre o(a) filho(a) e o companheiro. O item de outros vínculos também seria uma possível maneira de manter o anonimato do real autor da violência ${ }^{13}$.

A violência doméstica praticada seja por pais, ou familiares, ou responsáveis pela criança, é comum, e resulta da transgressão do poder do adulto sobre a criança ou adolescente, advinda, portanto, de uma hierarquia que permite que o agressor se aproveite da vulnerabilidade da criança por meio de chantagem, intimidação e silenciamento. Esta estrutura assimétrica de poder fundamenta-se na desigualdade geracional, pela diferença de faixa etária, e de gênero, que historicamente aprova a superioridade do homem adulto sobre crianças, principalmente meninas ${ }^{2,14}$.

Alguns fatores sustentam um pacto do silêncio na violência intrafamiliar, que são o difícil acesso à privacidade do ambiente familiar; sentimentos ambíguos na criança de medo, angústia e culpa e, ao mesmo tempo, de amor e confiança para com 
os familiares; medo e cumplicidade do(a) cônjuge, que não denuncia a violência; e omissão de pessoas externas à família, que tomam conhecimento da situação, mas decidem não expor a privacidade da família ou se preocupam com as consequências da revelação, inclusive pela falta de conhecimento sobre o que pode ser feito ${ }^{13-14}$.

\section{CONCLUSÕES}

A violência é um fenômeno multifacetado, verificada em todas as comunidades, desde a Antiguidade, resultado das interações individuais, coletivas, sociais e culturais presentes nas sociedades. Apresenta-se dentro de uma relação hierárquica de poder e dominação, especialmente contra as crianças, pela vulnerabilidade e dependência conferidas a elas, o que as torna categoricamente inferiores e predispostas a sofrerem violência.

Verificou-se neste estudo que a violência sexual infantil no Paraná apresentou aumento em número de notificações entre 2011 e 2014. Isso ocorreu devido às determinações do Ministério da Saúde, pela obrigatoriedade da notificação compulsória de violências a partir de 2011, ressaltando a importância das políticas públicas de combate à violência e o papel da vigilância epidemiológica no reconhecimento deste fenômeno tão complexo.

A maior prevalência da violência sexual infantil no Paraná foi observada na Regional de Foz do Iguaçu. Considerando-se as características individuais, as crianças violentadas sexualmente se encontram predominantemente na faixa etária de 5 a 9 anos, acometendo com maior prevalência as meninas e as crianças negras e indígenas. É importante destacar que isso reflete a construção histórica, social e cultural, intimamente arraigada nas desigualdades de gênero, étnico-raciais e geracionais.

O estupro foi a tipologia de violência sexual mais frequente, seguido pelo assédio sexual. Situação semelhante ocorre ao refletir-se sobre a categorização geral dos tipos de violência, pois na maioria dos casos ocorreu com agressão física por meio da força corporal/espancamento e agressão psicológica por meio de ameaça. O caráter doméstico da violência sexual infantil foi constatado neste estudo com $71,6 \%$ dos casos ocorrendo neste ambiente. Aliado a isso, $94,6 \%$ dos prováveis autores da violência são, de alguma forma, conhecidos ou próximos da criança ou da família.

Como limitação deste estudo, destaca-se a não disponibilidade e retroalimentação dos dados mais recentes pelo DATASUS. Esse estudo também possui relevância social, pois permite o conhecimento estatístico dos casos de violência sexual contra crianças no estado do Paraná. Recomenda-se que os determinantes que vulnerabilizam a criança para a violência sexual devam ser amplamente discutidos de forma intersetorial, para que as ações de prevenção, proteção e cuidado integral à infância sejam eficazes.

\section{REFERÊNCIAS}

1 - Brasil. Ministério da Saúde (MS). Secretaria de Atenção à Saúde. Linha de cuidado para a atenção integral à saúde de crianças, adolescentes e suas famílias em situação de violências: orientação para gestores e profissionais de saúde. Brasília: MS; 2010. [acesso em 20 jun 2018]. Disponível em: http://www.ensp.fiocruz.br/portal-ensp/ consulta-publica/arquivos/1393133501.pdf

2 - Sanches LC; Araújo G; Ramos M; Rozin L; Rauli PMF. Violência sexual infantil no Brasil: uma questão de saúde pública. Revista Iberoamericana de Bioética. 2019; 09:0113. [Acesso em 05 abr 2019]. Disponível em: https://revistas. comillas.edu/index.php/bioetica-revista-iberoamericana/ article/view/9654/10420

3 - Pires JMA. Injúrias Intencionais (Violências): Violência Sexual. Tratado de Pediatria, Sociedade Brasileira de Pediatria. 2 ed. Barueri, SP: Manole; 2010.

4 - Brasil. Ministério da Saúde. Secretaria de Vigilância em Saúde. Notificação de violências interpessoais e 
autoprovocadas. Brasília: MS; 2017. [Acesso em 20 Jun 2018]. Disponível em: http://bvsms.saude.gov.br/bvs/publicacoes/ notificacao_violencias_interpessoais_autoprovocadas.pdf

5 - Rates SMM, Melo EM, Mascarenhas MDM, Malta DC. Violência infantil: uma análise das notificações compulsórias, Brasil 2011. Ciênc. Saúde Colet. 2015; 20(3):655-665. [Acesso em 20 Jun 2018]. Disponível em: http:// www.scielo.br/scielo.php?script=sci_arttext\&pid=S1413$81232015000300655 \& \operatorname{lng}=$ en\&nrm=iso

6 - Garbin CAS, Dias IA, Rovida TAS, Garbin AJI. Desafios do profissional da saúde na notificação da violência: obrigatoriedade, efetivação e encaminhamento. Ciênc. Saúde Colet. 2015; 20(6):1879-1890. [Acesso em 20 Jun 2018]. Disponível em: http:/www.scielo.br/scielo.php?script=sci_ arttext\&pid=S1413-81232015000601879\&lng=en\&nrm=iso

7 - Zanette MHC, Silva EF. Implantação da ficha de notificação de violência doméstica, sexual e/ou outras violências na 9ª regional de saúde. Foz do Iguaçu/PR: Relato de Experiência. Caderno temático de vigilância de violências e acidentes no Paraná. Curitiba: SESA/SVS, 2014. [Acesso em: 20 Jun de 2018]. Disponível em: http://www.saude. pr.gov.br/arquivos/File/cadernoviolenciafinalarquivo2014. pdf

8 - Peres EL, Furtado MS, Mafioletti TM, Tisserant AE. A notificação de casos de violência doméstica e sexual contra a criança e o adolescente no Paraná: um panorama dos dados do SINAN-NET - Período de 2010 a 2012. Caderno temático de vigilância de violências e acidentes no Paraná. Curitiba: SESA/SVS, 2014. [Acesso em 28 Jun 2018]. Disponível em: http://www.saude.pr.gov.br/arquivos/ File/cadernoviolenciafinalarquivo2014.pdf

9 - Bortoli DM. Análise espacial dos atendimentos a crianças e adolescentes vulneráveis no município de Foz do Iguaçu. [Dissertação] Universidade Estadual do Oeste do Paraná, Foz do Iguaçu: Mestrado em Sociedade, Cultura e Fronteiras; 2015. [Acesso em 20 Jun 2018]. Disponível em: http://tede.unioeste.br/bitstream/tede/2572/1/Dayse_ Bortoli_2015.pdf

10 - Waiselfisz JJ. Mapa da violência 2012. Crianças e adolescentes do Brasil. CEBELA - Centro Brasileiro de Estudos Latino-Americanos. 1 ed. Rio de Janeiro: FLACSO; 2012.

11 - Assis SG, Avanci JQ, Pesce RP, Pires TO, Gomes DL. Notificações de violência doméstica, sexual e outras violências contra crianças no Brasil. Ciênc. Saúde Colet. 2012; 17(9):2305-2317. [Acesso em 20 Jun 2018]. Disponível em: http://www.scielo.br/scielo.php?script=sci_ arttext\&pid=S1413-81232012000900012\&lng=en\&nrm=iso

12 - Silva CB, Bastos BL, Santos CR, Moraes MS, Possuelo LG. Caracterização do perfil da violência sexual em crianças e adolescentes no Rio Grande do Sul. Rev. epidemiol. Controle infecç. 2016; 6. [Acesso em 20 Jun 2018]. Disponível em: https://online.unisc.br/seer/index. php/epidemiologia/article/view/8223

13 - Miranda MIF, Santos MAM, Tourinho MBAC, Watanabe CV, Miguel VVR, Santos GDN. Violência Sexual contra crianças e adolescentes em um município da Região Norte do Brasil. Rev. Soc. Bras. Enferm. Ped. 2014; 14(2):96-104. [Acesso em 20 Jun 2018]. Disponível em: https:/www.researchgate.net/profile/Carolina_ Watanabe/publication/275952399_Violencia_sexual_ contra_criancas_e_adolescentes_em_um_municipio_da Regiao_Norte_do_Brasil/links/554a76620cf21ed21358e620/ Violencia-sexual-contra-criancas-e-adolescentes-em-ummunicipio-da-Regiao-Norte-do-Brasil.pdf

14 - Oliveira HC, Pinto Junior EP, Tavares LT, Guimarães MAP, Oliveira MND. Notificação compulsória de violência sexual contra crianças e adolescentes. Arq. Ciênc. Saúde. 2015; 22(4):26-30. [Acesso em 12 Jun 2018]. Disponível em: https://www.researchgate.net/publication/288040745_ NOTIFICACAO_COMPULSORIA_DE_VIOLENCIA_ SEXUAL_CONTRA_CRIANCAS_E_ADOLESCENTES

15 - Platt VB, Back IC, Hauschild DB, Guedert JM. Violência sexual contra crianças: autores, vítimas e consequências. Ciênc. Saúde Colet. 2018; 23(4):1019-1031. [Acesso em 12 Jul 2018]. Disponível em: http://www.scielo.br/scielo. php?script=sci_arttext\&pid=S1413-81232018000401019\&ln $\mathrm{g}=\mathrm{en} \& \mathrm{nrm}=$ iso

16 - Almeida LAA, Sousa LS, Sousa KAA. Epidemiologia da violência infantil em um estado do nordeste do Brasil: série histórica de 2007 a 2016. Rev. Pre. Infec. e Saúde. 2017; 3(2):27-33. [Acesso em 15 Jun 2018]. Disponível em: http:// www.ojs.ufpi.br/index.php/nupcis/article/view/6457

17 - Gawryszewski VP, Valencich DMO, Carnevalle CV, Marcopito LF. Maus-tratos contra a criança e o adolescente no Estado de São Paulo, 2009. Rev. Assoc. Med. Bras. 2012; 58(6):659-665. Acesso em 12 Jul. 2018]. Disponível em: http:// www.scielo.br/scielo.php?script=sci_arttext\&pid=S0104$42302012000600009 \& \operatorname{lng}=\mathrm{en} \& \mathrm{nrm}=\mathrm{iso}$ 
18 - Farias MS, Souza CS, Carneseca EC, Passos ADC, Vieira EM. Caracterização das notificações de violência em crianças no município de Ribeirão Preto, São Paulo, no período 2006-2008. Epidemiol. Serv. Saúde. 2016; 25(4):799806. [Acesso em 18 Jun. 2018]. Disponível em: http:// www.scielo.br/scielo.php?script=sci_arttext\&pid=S223796222016000400799\&lng=en\&nrm=iso

19 - Malta DC, Bernal RTI, Teixeira BSM, Silva MMA, Freitas MIF. Fatores associados a violências contra crianças em Serviços Sentinela de Urgência nas capitais brasileiras. Ciênc. Saúde Colet. 2017; 22(9):2889-2898. [Acesso em 20 Jun. 2018]. Disponível em: http://www.scielo.br/scielo. php?script=sci_arttext\&pid=S1413-81232017002902889\&ln $\mathrm{g}=\mathrm{en} \& \mathrm{nrm}=\mathrm{iso}$

20 - Magalhães PH, Moreira DP, Lira SVG, Branco JGO, Tamboril BCR, Vieira LJES. Panorama da violência sexual contra crianças e adolescentes em municípios cearenses. Rev. Bras. Promoç. Saúde 2016; 29(3):414-421. [Acesso em 25 Jul. 2018]. Disponível em: http://periodicos.unifor.br/ RBPS/article/view/5253

21 - Cantú A. Crianças indígenas e a adoção. Criança indígena: olhar multidisciplinar. Campo Grande: Alvorada; 2012. 